\title{
Modified Noor's Extragradient Method for Solving Generalized Variational Inequalities in Banach Spaces
}

\author{
Shunhou Fan, ${ }^{1}$ Shin Min Kang, ${ }^{2}$ Muhammad Aslam Noor, ${ }^{3}$ and \\ Yonghong Yao $^{1}$
}

${ }^{1}$ Department of Mathematics, Tianjin Polytechnic University, Tianjin 300387, China

2 Department of Mathematics and RINS, Gyeongsang National University, Jinju 660-701, Republic of Korea

${ }^{3}$ Department of Mathematics, COMSATS Institute of Information Technology, Islamabad 44000, Pakistan

Correspondence should be addressed to Shin Min Kang, smkang@gnu.ac.kr

Received 9 January 2012; Accepted 20 January 2012

Academic Editor: Khalida Inayat Noor

Copyright (C) 2012 Shunhou Fan et al. This is an open access article distributed under the Creative Commons Attribution License, which permits unrestricted use, distribution, and reproduction in any medium, provided the original work is properly cited.

Motivated and inspired by Korpelevich's and Noor's extragradient methods, we suggest an extragradient method by using the sunny nonexpansive retraction which has strong convergence for solving the generalized variational inequalities in Banach spaces.

\section{Introduction}

In the present paper, we focus on the following generalized variational inequality:

$$
\text { Find } x^{*} \in C \text { such that }\left\langle A x^{*}, J\left(x-x^{*}\right)\right\rangle \geq 0, \quad \forall x \in C \text {, }
$$

where $C$ is a nonempty closed convex subset of a real Banach space $E, A: C \rightarrow E$ is a nonlinear mapping, and $J: E \rightarrow 2^{E^{*}}$ is the normalized duality mapping defined by

$$
J(x)=\left\{f \in E^{*}:\langle x, f\rangle=\|x\|^{2},\|f\|=\|x\|\right\}, \quad \forall x \in E .
$$

We use $S(C, A)$ to denote the solution set of (1.1). It is clear that (1.1) is reduced to the following variational inequality in Hilbert spaces:

$$
\text { Find } x^{*} \in C \text { such that }\left\langle A x^{*}, x-x^{*}\right\rangle \geq 0, \quad \forall x \in C \text {, }
$$


which was introduced and studied by Stampacchia [1]. Variational inequalities are being used as mathematical programming tools and models to study a wide class of unrelated problems arising in mathematical, physical, regional, engineering, and nonlinear optimization sciences. See, for instance, [2-23]. In order to solve (1.3), especially, Korpelevich [24] introduced the following well-known extragradient method:

$$
\begin{gathered}
y_{n}=P_{C}(I-\lambda A) x_{n}, \\
x_{n+1}=P_{C}\left(x_{n}-\lambda A y_{n}\right), \quad n \geq 0,
\end{gathered}
$$

where $P_{C}$ is the metric projection from $R^{n}$ onto its subset $C, \lambda \in(0,1 / k)$ and $A: C \rightarrow R^{n}$ is a monotone operator. He showed that the sequence $\left\{x_{n}\right\}$ converges to some solution of the above variational inequality (1.3). Noor [10] further suggested and analyzed the following new iterative methods:

$$
\begin{gathered}
x_{n+1}=P_{C}\left(y_{n}-\lambda A y_{n}\right), \\
y_{n}=P_{C}\left[x_{n}-\lambda A x_{n}\right], \quad n \geq 0,
\end{gathered}
$$

which is known as the modified Noor's extragradient method. We would like to point out that this algorithm (1.5) is quite different from the method of Koperlevich. However, these two algorithms fail, in general, to converge strongly in the setting of infinite-dimensional Hilbert spaces.

The generalized variational inequality (1.1) was introduced by Aoyama et al. [25] which is connected with the fixed point problem for nonlinear mapping. For solving the aforementioned generalized variational inequality (1.1), Aoyama et al. [25] introduced an iterative algorithm:

$$
x_{n+1}=\alpha_{n} x_{n}+\left(1-\alpha_{n}\right) Q_{C}\left[x_{n}-\lambda_{n} A x_{n}\right], \quad n \geq 0,
$$

where $Q_{C}$ is a sunny nonexpansive retraction from $E$ onto $C$, and $\left\{\alpha_{n}\right\} \subset(0,1)$ and $\left\{\lambda_{n}\right\} \subset$ $(0, \infty)$ are two real number sequences. Aoyama et al. [25] obtained on the aforementioned method (1.6) for solving variational inequality (1.1). Motivated by (1.6), Yao and Maruster [26] presented a modification of (1.5):

$$
x_{n+1}=\beta_{n} x_{n}+\left(1-\beta_{n}\right) Q_{C}\left[\left(1-\alpha_{n}\right)\left(x_{n}-\lambda A x_{n}\right)\right], \quad n \geq 0 .
$$

Yao and Maruster [26] proved that (1.7) converges strongly to the solution of the generalized variational inequality (1.1). Yao et al. [27] further considered the following extended extragradient method for solving (1.1):

$$
\begin{aligned}
y_{n} & =Q_{C}\left[x_{n}-\lambda_{n} A x_{n}\right], \\
x_{n+1} & =\alpha_{n} u+\beta_{n} x_{n}+\gamma_{n} Q_{C}\left[y_{n}-\lambda A y_{n}\right], \quad n \geq 0 .
\end{aligned}
$$

In this paper, motivated and inspired by Korpelevich's and Noor's extragradient methods, (1.7) and (1.8), we suggest a modified Noor's extragradient method via the sunny nonexpansive retraction for solving the variational inequalities (1.1) in Banach spaces. 


\section{Preliminaries}

Let $C$ be a nonempty closed convex subset of a real Banach space $E$. Recall that a mapping $A$ of $C$ into $E$ is said to be accretive if there exists $j(x-y) \in J(x-y)$ such that

$$
\langle A x-A y, j(x-y)\rangle \geq 0
$$

for all $x, y \in C$. A mapping $A$ of $C$ into $E$ is said to be $\alpha$-strongly accretive if, for $\alpha>0$,

$$
\langle A x-A y, j(x-y)\rangle \geq \alpha\|x-y\|^{2}
$$

for all $x, y \in C$. A mapping $A$ of $C$ into $E$ is said to be $\alpha$-inverse-strongly accretive if, for $\alpha>0$,

$$
\langle A x-A y, j(x-y)\rangle \geq \alpha\|A x-A y\|^{2},
$$

for all $x, y \in C$.

Let $U=\{x \in E:\|x\|=1\}$. A Banach space $E$ is said to uniformly convex if, for each $\epsilon \in(0,2]$, there exists $\delta>0$ such that for any $x, y \in U$,

$$
\|x-y\| \geq \epsilon \text { implies }\left\|\frac{x+y}{2}\right\| \leq 1-\delta .
$$

It is known that a uniformly convex Banach space is reflexive and strictly convex. A Banach space $E$ is said to be smooth if the limit

$$
\lim _{t \rightarrow 0} \frac{\|x+t y\|-\|x\|}{t}
$$

exists for all $x, y \in U$. It is also said to be uniformly smooth if the limit (2.5) is attained uniformly for $x, y \in U$. The norm of $E$ is said to be Fréchet differentiable if, for each $x \in U$, the limit $(2.5)$ is attained uniformly for $y \in U$. And we define a function $\rho:[0, \infty) \rightarrow[0, \infty)$ called the modulus of smoothness of $E$ as follows:

$$
\rho(\tau)=\sup \left\{\frac{1}{2}(\|x+y\|+\|x-y\|)-1: x, y \in X,\|x\|=1,\|y\|=\tau\right\} .
$$

It is known that $E$ is uniformly smooth if and only if $\lim _{\tau \rightarrow 0}(\rho(\tau) / \tau)=0$. Let $q$ be a fixed real number with $1<q \leq 2$. Then a Banach space $E$ is said to be $q$-uniformly smooth if there exists a constant $c>0$ such that $\rho(\tau) \leq c \tau^{q}$ for all $\tau>0$.

We need the following lemmas for proof of our main results.

Lemma 2.1 (see [28]). Let $q$ be a given real number with $1<q \leq 2$ and let $E$ be a q-uniformly smooth Banach space. Then

$$
\|x+y\|^{q} \leq\|x\|^{q}+q\left\langle y, J_{q}(x)\right\rangle+2\|K y\|^{q}
$$


for all $x, y \in E$, where $K$ is the $q$-uniformly smoothness constant of $E$ and $J_{q}$ is the generalized duality mapping from $E$ into $2^{E^{*}}$ defined by

$$
J_{q}(x)=\left\{f \in E^{*}:\langle x, f\rangle=\|x\|^{q},\|f\|=\|x\|^{q-1}\right\}, \quad \forall x \in E .
$$

Let $D$ be a subset of $C$ and let $Q$ be a mapping of $C$ into $D$. Then $Q$ is said to be sunny if

$$
Q(Q x+t(x-Q x))=Q x
$$

whenever $Q x+t(x-Q x) \in C$ for $x \in C$ and $t \geq 0$. A mapping $Q$ of $C$ into itself is called a retraction if $Q^{2}=Q$. If a mapping $Q$ of $C$ into itself is a retraction, then $Q z=z$ for every $z \in R(Q)$, where $R(Q)$ is the range of $Q$. A subset $D$ of $C$ is called a sunny nonexpansive retract of $C$ if there exists a sunny nonexpansive retraction from $C$ onto $D$. One knows the following lemma concerning sunny nonexpansive retraction.

Lemma 2.2 (see [29]). Let $C$ be a closed convex subset of a smooth Banach space E, let $D$ be a nonempty subset of $C$, and let $Q$ be a retraction from $C$ onto $D$. Then $Q$ is sunny and nonexpansive if and only if

$$
\langle u-Q u, j(y-Q u)\rangle \leq 0
$$

for all $u \in C$ and $y \in D$.

Remark 2.3. (1) It is well known that if $E$ is a Hilbert space, then a sunny nonexpansive retraction $Q_{C}$ is coincident with the metric projection from $E$ onto $C$.

(2) Let $C$ be a nonempty closed convex subset of a uniformly convex and uniformly smooth Banach space $E$ and let $T$ be a nonexpansive mapping of $C$ into itself with $F(T) \neq \emptyset$. Then the set $F(T)$ is a sunny nonexpansive retract of $C$.

The following lemma characterized the set of solution of (1.1) by using sunny nonexpansive retractions.

Lemma 2.4 (see [25]). Let $C$ be a nonempty closed convex subset of a smooth Banach space X. Let $Q_{C}$ be a sunny nonexpansive retraction from $X$ onto $C$ and let $A$ be an accretive operator of $C$ into $X$. Then for all $\lambda>0$,

$$
S(C, A)=F\left(Q_{C}(I-\lambda A)\right)
$$

where $S(C, A)=\left\{x^{*} \in C:\left\langle A x^{*}, J\left(x-x^{*}\right)\right\rangle \geq 0, \forall x \in C\right\}$.

Lemma 2.5 (see [30]). Let $C$ be a nonempty bounded closed convex subset of a uniformly convex Banach space $E$ and let $T$ be nonexpansive mapping of $C$ into itself. If $\left\{x_{n}\right\}$ is a sequence of $C$ such that $x_{n} \rightarrow x$ weakly and $x_{n}-T x_{n} \rightarrow 0$ strongly, then $x$ is a fixed point of $T$.

Lemma 2.6 (see [31]). Assume that $\left\{a_{n}\right\}$ is a sequence of nonnegative real numbers such that

$$
a_{n+1} \leq\left(1-\gamma_{n}\right) a_{n}+\delta_{n}, \quad n \geq 0
$$


where $\left\{\gamma_{n}\right\}$ is a sequence in $(0,1)$ and $\left\{\delta_{n}\right\}$ is a sequence in $R$ such that

(a) $\sum_{n=0}^{\infty} \gamma_{n}=\infty$;

(b) $\lim \sup _{n \rightarrow \infty}\left(\delta_{n} / \gamma_{n}\right) \leq 0$ or $\sum_{n=0}^{\infty}\left|\delta_{n}\right|<\infty$.

Then $\lim _{n \rightarrow \infty} a_{n}=0$.

\section{Main Results}

In this section, we will state and prove our main result.

Theorem 3.1. Let E be a uniformly convex and 2-uniformly smooth Banach space and let $C$ be a nonempty closed convex subset of $E$. Let $Q_{C}$ be a sunny nonexpansive retraction from $E$ onto $C$ and let $A: C \rightarrow E$ be an $\alpha$-strongly accretive and L-Lipschitz continuous mapping with $S(C, A) \neq \emptyset$. For given $x_{0} \in C$, let the sequence $\left\{x_{n}\right\}$ be generated iteratively by

$$
\begin{gathered}
y_{n}=Q_{C}\left[x_{n}-\lambda A x_{n}\right], \\
x_{n+1}=Q_{C}\left[\left(1-\alpha_{n}\right)\left(y_{n}-\lambda A y_{n}\right)\right], \quad n \geq 0,
\end{gathered}
$$

where $\left\{\alpha_{n}\right\}$ and $\left\{\beta_{n}\right\}$ are two sequences in $(0,1)$ and $\lambda$ is a constant in $[a, b]$ for some $a, b$ with $0<a<b<\alpha / K^{2} L^{2}$. Assume that the following conditions hold:

(a) $\lim _{n \rightarrow \infty} \alpha_{n}=0$ and $\sum_{n=1}^{\infty} \alpha_{n}=\infty$;

(b) $\lim _{n \rightarrow \infty}\left(\alpha_{n+1} / \alpha_{n}\right)=1$.

Then $\left\{x_{n}\right\}$ defined by (3.1) converges strongly to $Q^{\prime}(0)$, where $Q^{\prime}$ is a sunny nonexpansive retraction of $E$ onto $S(C, A)$.

Proof. First, we note that $A$ must be $\alpha / L^{2}$-inverse-strongly accretive mapping. Take $p \in$ $S(C, A)$. By using Lemmas 2.1 and 2.4, we easily obtain the following facts.

(1) $p=Q_{C}[p-\lambda A p]$ for all $\lambda>0$; in particular,

$$
p=Q_{C}\left[p-\lambda\left(1-\alpha_{n}\right) A p\right]=Q_{C}\left[\alpha_{n} p+\left(1-\alpha_{n}\right)(p-\lambda A p)\right], \quad n \geq 0 .
$$

(2) If $\lambda \in\left(0, \alpha / K^{2} L^{2}\right]$, then $I-\lambda A$ is nonexpansive and for all $x, y \in C$

$$
\|(I-\lambda A) x-(I-\lambda A) y\|^{2} \leq\|x-y\|^{2}+2 \lambda\left(K^{2} \lambda-\frac{\alpha}{L^{2}}\right)\|A x-A y\|^{2} .
$$

Indeed, from Lemma 2.1, we have

$$
\begin{aligned}
\|(I-\lambda A) x-(I-\lambda A) y\|^{2} & =\|(x-y)-\lambda(A x-A y)\|^{2} \\
& \leq\|x-y\|^{2}-2 \lambda\langle A x-A y, j(x-y)\rangle+2 K^{2} \lambda^{2}\|A x-A y\|^{2} \\
& \leq\|x-y\|^{2}-2 \lambda \frac{\alpha}{L^{2}}\|A x-A y\|^{2}+2 K^{2} \lambda^{2}\|A x-A y\|^{2} \\
& =\|x-y\|^{2}+2 \lambda\left(K^{2} \lambda-\frac{\alpha}{L^{2}}\right)\|A x-A y\|^{2} .
\end{aligned}
$$


From (3.1), we have

$$
\begin{aligned}
\left\|y_{n}-p\right\| & =\left\|Q_{C}\left(x_{n}-\lambda A x_{n}\right)-Q_{C}(p-\lambda A p)\right\| \\
& \leq\left\|\left(x_{n}-\lambda A x_{n}\right)-(p-\lambda A p)\right\| \\
& \leq\left\|x_{n}-p\right\| .
\end{aligned}
$$

By (3.1) and (3.5), we have

$$
\begin{aligned}
\left\|x_{n+1}-p\right\| & =\left\|Q_{C}\left[\left(1-\alpha_{n}\right)\left(y_{n}-\lambda A y_{n}\right)\right]-Q_{C}\left[\alpha_{n} p+\left(1-\alpha_{n}\right)(p-\lambda A p)\right]\right\| \\
& \leq\left\|\left[\left(1-\alpha_{n}\right)\left(y_{n}-\lambda A y_{n}\right)\right]-\left[\alpha_{n} p+\left(1-\alpha_{n}\right)(p-\lambda A p)\right]\right\| \\
& \leq \alpha_{n}\|p\|+\left(1-\alpha_{n}\right)\left\|\left(y_{n}-\lambda A y_{n}\right)-(p-\lambda A p)\right\| \\
& \leq \alpha_{n}\|p\|+\left(1-\alpha_{n}\right)\left\|y_{n}-p\right\| \\
& \leq \alpha_{n}\|p\|+\left(1-\alpha_{n}\right)\left\|x_{n}-p\right\| \\
& \leq \max \left\{\|p\|,\left\|x_{0}-p\right\|\right\} .
\end{aligned}
$$

Therefore, $\left\{x_{n}\right\}$ is bounded. We observe that

$$
\begin{aligned}
\left\|y_{n}-y_{n-1}\right\| & =\left\|Q_{C}\left[x_{n}-\lambda A x_{n}\right]-Q_{C}\left[x_{n-1}-\lambda A x_{n-1}\right]\right\| \\
& \leq\left\|\left(x_{n}-\lambda A x_{n}\right)-\left(x_{n-1}-\lambda A x_{n-1}\right)\right\| \\
& \leq\left\|x_{n}-x_{n-1}\right\|,
\end{aligned}
$$

and hence

$$
\begin{aligned}
\left\|x_{n+1}-x_{n}\right\| & =\left\|Q_{C}\left[\left(1-\alpha_{n}\right)\left(y_{n}-\lambda A y_{n}\right)\right]-Q_{C}\left[\left(1-\alpha_{n-1}\right)\left(y_{n-1}-\lambda A y_{n-1}\right)\right]\right\| \\
& \leq\left\|\left[\left(1-\alpha_{n}\right)\left(y_{n}-\lambda A y_{n}\right)\right]-\left[\left(1-\alpha_{n-1}\right)\left(y_{n-1}-\lambda A y_{n-1}\right)\right]\right\| \\
& =\left\|\left(1-\alpha_{n}\right)\left[\left(y_{n}-\lambda A y_{n}\right)-\left(y_{n-1}-\lambda A y_{n-1}\right)\right]+\left(\alpha_{n-1}-\alpha_{n}\right)\left(y_{n-1}-\lambda A y_{n-1}\right)\right\| \\
& \leq\left(1-\alpha_{n}\right)\left\|\left(y_{n}-\lambda A y_{n}\right)-\left(y_{n-1}-\lambda A y_{n-1}\right)\right\|+\left|\alpha_{n}-\alpha_{n-1}\right|\left\|y_{n-1}-\lambda A y_{n-1}\right\| \\
& \leq\left(1-\alpha_{n}\right)\left\|y_{n}-y_{n-1}\right\|+\left|\alpha_{n}-\alpha_{n-1}\right|\left\|y_{n-1}-\lambda A y_{n-1}\right\| \\
& \leq\left(1-\alpha_{n}\right)\left\|x_{n}-x_{n-1}\right\|+\left|\alpha_{n}-\alpha_{n-1}\right|\left\|y_{n-1}-\lambda A y_{n-1}\right\| .
\end{aligned}
$$

By Lemma 2.6, we obtain

$$
\lim _{n \rightarrow \infty}\left\|x_{n+1}-x_{n}\right\|=0
$$


From (3.1), we also have

$$
\begin{aligned}
\left\|y_{n}-p\right\|^{2} & =\left\|Q_{C}\left[x_{n}-\lambda A x_{n}\right]-Q_{C}[p-\lambda A p]\right\|^{2} \\
& \leq\left\|\left(x_{n}-\lambda A x_{n}\right)-(p-\lambda A p)\right\|^{2} \\
& \leq\left\|x_{n}-p\right\|^{2}+2 \lambda\left(K^{2} \lambda-\frac{\alpha}{L^{2}}\right)\left\|A x_{n}-A p\right\|^{2} .
\end{aligned}
$$

By (3.1) and (3.10), we obtain

$$
\begin{aligned}
\left\|x_{n+1}-p\right\|^{2} \leq & \left\|\alpha_{n}(-p)+\left(1-\alpha_{n}\right)\left[\left(y_{n}-\lambda A y_{n}\right)-(p-\lambda A p)\right]\right\|^{2} \\
\leq & \alpha_{n}\|p\|^{2}+\left(1-\alpha_{n}\right)\left\|\left(y_{n}-\lambda A y_{n}\right)-(p-\lambda A p)\right\|^{2} \\
\leq & \alpha_{n}\|p\|^{2}+\left(1-\alpha_{n}\right)\left[\left\|y_{n}-p\right\|^{2}+2 \lambda\left(K^{2} \lambda-\frac{\alpha}{L^{2}}\right)\left\|A y_{n}-A p\right\|^{2}\right] \\
\leq & \alpha_{n}\|p\|^{2}+\left(1-\alpha_{n}\right)\left[\left\|x_{n}-p\right\|^{2}+2 \lambda\left(K^{2} \lambda-\frac{\alpha}{L^{2}}\right)\left\|A x_{n}-A p\right\|^{2}\right] \\
& +2\left(1-\alpha_{n}\right) \lambda\left(K^{2} \lambda-\frac{\alpha}{L^{2}}\right)\left\|A y_{n}-A p\right\|^{2} \\
\leq & \alpha_{n}\|p\|^{2}+\left\|x_{n}-p\right\|^{2}+2\left(1-\alpha_{n}\right) \lambda\left(K^{2} \lambda-\frac{\alpha}{L^{2}}\right)\left\|A x_{n}-A p\right\|^{2} \\
& +2\left(1-\alpha_{n}\right) \lambda\left(K^{2} \lambda-\frac{\alpha}{L^{2}}\right)\left\|A y_{n}-A p\right\|^{2} .
\end{aligned}
$$

Therefore, we have

$$
\begin{aligned}
0 & \leq-2\left(1-\alpha_{n}\right) \lambda\left(K^{2} \lambda-\frac{\alpha}{L^{2}}\right)\left\|A x_{n}-A p\right\|^{2}-2\left(1-\alpha_{n}\right) \lambda\left(K^{2} \lambda-\frac{\alpha}{L^{2}}\right)\left\|A y_{n}-A p\right\|^{2} \\
& \leq \alpha_{n}\|p\|^{2}+\left\|x_{n}-p\right\|^{2}-\left\|x_{n+1}-p\right\|^{2} \\
& =\alpha_{n}\|p\|^{2}+\left(\left\|x_{n}-p\right\|+\left\|x_{n+1}-p\right\|\right)\left(\left\|x_{n}-p\right\|-\left\|x_{n+1}-p\right\|\right) \\
& \leq \alpha_{n}\|p\|^{2}+\left(\left\|x_{n}-p\right\|+\left\|x_{n+1}-p\right\|\right)\left\|x_{n}-x_{n+1}\right\| .
\end{aligned}
$$

Since $\liminf \inf _{n \rightarrow \infty} 2\left(1-\alpha_{n}\right) \lambda\left(K^{2} \lambda-\alpha / L^{2}\right)>0, \alpha_{n} \rightarrow 0$ and $\left\|x_{n}-x_{n+1}\right\| \rightarrow 0$, we obtain

$$
\lim _{n \rightarrow \infty}\left\|A x_{n}-A p\right\|=\lim _{n \rightarrow \infty}\left\|A y_{n}-A p\right\|=0 .
$$

It follows that

$$
\lim _{n \rightarrow \infty}\left\|A y_{n}-A x_{n}\right\|=0
$$

Since $A$ is $\alpha$-strongly accretive, we deduce

$$
\left\|A y_{n}-A x_{n}\right\| \geq \alpha\left\|y_{n}-x_{n}\right\|
$$


which implies that

$$
\lim _{n \rightarrow \infty}\left\|y_{n}-x_{n}\right\|=0
$$

that is,

$$
\lim _{n \rightarrow \infty}\left\|Q_{C}\left(x_{n}-\lambda A x_{n}\right)-x_{n}\right\|=0
$$

Next, we show that

$$
\limsup _{n \rightarrow \infty}\left\langle Q^{\prime}(0), j\left(x_{n}-Q^{\prime}(0)\right)\right\rangle \geq 0
$$

To show (3.18), since $\left\{x_{n}\right\}$ is bounded, we can choose that a sequence $\left\{x_{n_{i}}\right\}$ of $\left\{x_{n}\right\}$ converges weakly to $z$ such that

$$
\limsup _{n \rightarrow \infty}\left\langle Q^{\prime}(0), j\left(x_{n}-Q^{\prime}(0)\right)\right\rangle=\limsup _{i \rightarrow \infty}\left\langle Q^{\prime}(0), j\left(x_{n_{i}}-Q^{\prime}(0)\right)\right\rangle
$$

We first prove $z \in S(C, A)$. It follows that

$$
\lim _{i \rightarrow \infty}\left\|Q_{C}(I-\lambda A) x_{n_{i}}-x_{n_{i}}\right\|=0
$$

By Lemma 2.5 and (3.20), we have $z \in F\left(Q_{C}(I-\lambda A)\right)$; it follows from Lemma 2.4 that $z \in$ $S(C, A)$.

Now, from (3.19) and Lemma 2.2, we have

$$
\begin{aligned}
\limsup _{n \rightarrow \infty}\left\langle Q^{\prime}(0), j\left(x_{n}-Q^{\prime}(0)\right)\right\rangle & =\limsup _{i \rightarrow \infty}\left\langle Q^{\prime}(0), j\left(x_{n_{i}}-Q^{\prime}(0)\right)\right\rangle \\
& =\left\langle Q^{\prime}(0), j\left(z-Q^{\prime}(0)\right)\right\rangle \\
& \geq 0
\end{aligned}
$$

Since $x_{n+1}=Q_{C}\left[\left(1-\alpha_{n}\right)\left(y_{n}-\lambda A y_{n}\right)\right]$ and $x^{*}=Q_{C}\left[\alpha_{n} x^{*}+\left(1-\alpha_{n}\right)\left(x^{*}-\lambda A x^{*}\right)\right]$ for all $n \geq 0$, we can deduce from Lemma 2.2 that

$$
\begin{gathered}
\left\langle Q_{C}\left[\left(1-\alpha_{n}\right)\left(y_{n}-\lambda_{n} A y_{n}\right)\right]-\left[\left(1-\alpha_{n}\right)\left(y_{n}-\lambda_{n} A y_{n}\right)\right], j\left(x_{n+1}-x^{*}\right)\right\rangle \leq 0, \\
\left\langle\left[\alpha_{n} x^{*}+\left(1-\alpha_{n}\right)\left(x^{*}-\lambda_{n} A x^{*}\right)\right]-Q_{C}\left[\alpha_{n} x^{*}+\left(1-\alpha_{n}\right)\left(x^{*}-\lambda_{n} A x^{*}\right)\right], j\left(x_{n+1}-x^{*}\right)\right\rangle \leq 0 .
\end{gathered}
$$


Therefore, we have

$$
\begin{aligned}
\left\|x_{n+1}-x^{*}\right\|^{2}= & \left\langle Q_{C}\left[\left(1-\alpha_{n}\right)\left(y_{n}-\lambda_{n} A y_{n}\right)\right]-Q_{C}\left[\alpha_{n} x^{*}+\left(1-\alpha_{n}\right)\left(x^{*}-\lambda_{n} A x^{*}\right)\right], j\left(x_{n+1}-x^{*}\right)\right\rangle \\
= & \left\langle Q_{C}\left[\left(1-\alpha_{n}\right)\left(y_{n}-\lambda_{n} A y_{n}\right)\right]-\left[\left(1-\alpha_{n}\right)\left(y_{n}-\lambda_{n} A y_{n}\right)\right], j\left(x_{n+1}-x^{*}\right)\right\rangle \\
& +\left\langle\left[\left(1-\alpha_{n}\right)\left(y_{n}-\lambda_{n} A y_{n}\right)\right]-\left[\alpha_{n} x^{*}+\left(1-\alpha_{n}\right)\left(x^{*}-\lambda_{n} A x^{*}\right)\right], j\left(x_{n+1}-x^{*}\right)\right\rangle \\
& +\left\langle\left[\alpha_{n} x^{*}+\left(1-\alpha_{n}\right)\left(x^{*}-\lambda_{n} A x^{*}\right)\right]-Q_{C}\left[\alpha_{n} x^{*}+\left(1-\alpha_{n}\right)\left(x^{*}-\lambda_{n} A x^{*}\right)\right], j\left(x_{n+1}-x^{*}\right)\right\rangle \\
\leq & \left\langle\left(1-\alpha_{n}\right)\left(y_{n}-\lambda_{n} A y_{n}\right)-\left(1-\alpha_{n}\right)\left(x^{*}-\lambda_{n} A x^{*}\right)-\alpha_{n} x^{*}, j\left(x_{n+1}-x^{*}\right)\right\rangle \\
\leq & \left(1-\alpha_{n}\right)\left\|y_{n}-x^{*}\right\|\left\|x_{n+1}-x^{*}\right\|-\alpha_{n}\left\langle x^{*}, j\left(x_{n+1}-x^{*}\right)\right\rangle \\
\leq & \left(1-\alpha_{n}\right)\left\|x_{n}-x^{*}\right\|\left\|x_{n+1}-x^{*}\right\|-\alpha_{n}\left\langle x^{*}, j\left(x_{n+1}-x^{*}\right)\right\rangle \\
\leq & \frac{1-\alpha_{n}}{2}\left(\left\|x_{n}-x^{*}\right\|^{2}+\left\|x_{n+1}-x^{*}\right\|^{2}\right)-\alpha_{n}\left\langle x^{*}, j\left(x_{n+1}-x^{*}\right)\right\rangle,
\end{aligned}
$$

which implies that

$$
\left\|x_{n+1}-z\right\|^{2} \leq\left(1-\alpha_{n}\right)\left\|x_{n}-z\right\|^{2}+2 \alpha_{n}\left\langle-z, j\left(x_{n+1}-z\right)\right\rangle .
$$

Finally, by Lemma 2.6 and (3.24), we conclude that $x_{n}$ converges strongly to $Q^{\prime}(0)$. This completes the proof.

\section{Conclusion}

Variational inequality theory provides a simple, natural, and unified framework for a general treatment of unrelated problems. These activities have motivated to generalize and extend the variational inequalities and related optimization problems in several directions using new and novel techniques. A well-known method to solve the VI is the following gradient method:

$$
x_{n+1}=P_{C}\left(x_{n}-\alpha_{n} A\left(x_{n}\right)\right), \quad n \geq 0,
$$

This method requires some monotonicity properties of $A$. However, we remark that there is no chance of relaxing the assumption on $A$ to plain monotonicity. To overcome this weakness of the method, Korpelevich proposed a so-called Korpelevich's method which has been extensively extended and studied. Noor [10] especially, suggested another method referred as Noor's method which is different from Korpelevich's method. However, these two algorithms fail, in general, to converge strongly in the setting of infinite-dimensional Hilbert spaces. In the present paper, we suggested a modified Noor's method which has strong convergence in Banach spaces. We hope that the ideas and technique of this paper may stimulate further research in this field.

\section{Acknowledgment}

The authors thank the referees for useful comments and suggestions. 


\section{References}

[1] G. Stampacchia, "Formes bilineaires coercitives sur les ensembles convexes," Comptes Rendus de l'Academie des Sciences, vol. 258, pp. 4413-4416, 1964.

[2] Y. Censor, A. N. Iusem, and S. A. Zenios, "An interior point method with Bregman functions for the variational inequality problem with paramonotone operators," Mathematical Programming A, vol. 81, no. 3, pp. 373-400, 1998.

[3] R. Glowinski, Numerical Methods for Nonlinear Variational Problems, Springer-Verlag, New York, NY, USA, 1984.

[4] A. N. Iusem, "An iterative algorithm for the variational inequality problem," Computational and Applied Mathematics, vol. 13, no. 2, pp. 103-114, 1994.

[5] P. Jaillet, D. Lamberton, and B. Lapeyre, "Variational inequalities and the pricing of American options," Acta Applicandae Mathematicae, vol. 21, no. 3, pp. 263-289, 1990.

[6] M. A. Noor, On Variational Inequalities, Brunel University, London, UK, 1975.

[7] M. A. Noor, "General variational inequalities," Applied Mathematics Letters, vol. 1, no. 2, pp. 119-122, 1988.

[8] M. A. Noor, "Wiener-Hopf equations and variational inequalities," Journal of Optimization Theory and Applications, vol. 79, no. 1, pp. 197-206, 1993.

[9] M. A. Noor, "New approximation schemes for general variational inequalities," Journal of Mathematical Analysis and Applications, vol. 251, no. 1, pp. 217-229, 2000.

[10] M. A. Noor, "A class of new iterative methods for general mixed variational inequalities," Mathematical and Computer Modelling, vol. 31, no. 13, pp. 11-19, 2000.

[11] M. A. Noor, "Some developments in general variational inequalities," Applied Mathematics and Computation, vol. 152, no. 1, pp. 199-277, 2004.

[12] M. A. Noor, "Extended general variational inequalities," Applied Mathematics Letters, vol. 22, no. 2, pp. 182-186, 2009.

[13] M. A. Noor, "Some aspects of extended general variational inequalities," Abstract and Applied Analysis, vol. 2012, Article ID 303569, 16 pages, 2012.

[14] M. A. Noor and E. A. Al-Said, “Wiener-Hopf equations technique for quasimonotone variational inequalities," Journal of Optimization Theory and Applications, vol. 103, no. 3, pp. 705-714, 1999.

[15] M. Aslam Noor and Z. Huang, "Wiener-Hopf equation technique for variational inequalities and nonexpansive mappings," Applied Mathematics and Computation, vol. 191, no. 2, pp. 504-510, 2007.

[16] M. A. Noor, K. I. Noor, and E. Al-Said, "Iterative methods for solving nonconvex equilibrium variational inequalities," Applied Mathematics and Information Sciences, vol. 6, no. 1, pp. 65-69, 2012.

[17] H. K. Xu and T. H. Kim, "Convergence of hybrid steepest-descent methods for variational inequalities," Journal of Optimization Theory and Applications, vol. 119, no. 1, pp. 185-201, 2003.

[18] I. Yamada, "The hybrid steepest descent method for the variational inequality problem over the intersection of fixed point sets of nonexpansive mappings," in Inherently Parallel Algorithms in Feasibility and Optimization and Their Applications, D. Butnariu, Y. Censor, and S. Reich, Eds., vol. 8, pp. 473-504, North-Holland, Amsterdam, Holland, 2001.

[19] J. C. Yao, "Variational inequalities with generalized monotone operators," Mathematics of Operations Research, vol. 19, no. 3, pp. 691-705, 1994.

[20] Y. Yao, Y.-C. Liou, and S. M. Kang, “Two-step projection methods for a system of variational inequality problems in Banach spaces," Journal of Global Optimization. In press.

[21] Y. Yao, M. A. Noor, and Y.-C Liou, "Strong convergence of a modified extra-gradient method to the minimum-norm solution of variational inequalities," Abstract and Applied Analysis, vol. 2012, Article ID 817436, 9 pages, 2012.

[22] Y. Yao, M. A. Noor, and Y.-C Liou, "Iterative algorithms for general multi-valued variational inequalities," Abstract and Applied Analysis, vol. 2012, Article ID 768272, 10 pages, 2012.

[23] E. Zeidler, Nonlinear Functional Analysis and its Applications. III: Variational Methods and Applications, Springer-Verlag, New York, NY, USA, 1985.

[24] G. M. Korpelevich, "An extragradient method for finding saddle points and for other problems," Ekonomika i Matematicheskie Metody, vol. 12, no. 4, pp. 747-756, 1976.

[25] K. Aoyama, H. Iiduka, and W. Takahashi, "Weak convergence of an iterative sequence for accretive operators in Banach spaces," Fixed Point Theory and Applications, vol. 2006, Article ID 35390, 13 pages, 2006.

[26] Y. Yao and S. Maruster, "Strong convergence of an iterative algorithm for variational inequalities in Banach spaces," Mathematical and Computer Modelling, vol. 54, no. 1-2, pp. 325-329, 2011. 
[27] Y. Yao, Y. C. Liou, C. L. Li, and H. T. Lin, “Extended extragradient methods for generalized variational inequalities," Journal of Applied Mathematics, vol. 2012, Article ID 237083, 14 pages, 2012.

[28] H. K. Xu, "Inequalities in Banach spaces with applications," Nonlinear Analysis. Theory, Methods $\mathcal{E}$ Applications, vol. 16, no. 12, pp. 1127-1138, 1991.

[29] R. E. Bruck Jr., "Nonexpansive retracts of Banach spaces," Bulletin of the American Mathematical Society, vol. 76, pp. 384-386, 1970.

[30] F. E. Browder, "Nonlinear operators and nonlinear equations of evolution in Banach spaces," in Nonlinear Functional Analysis (Proceedings of Symposia in Pure Mathematics, Vol. XVIII, Part 2, Chicago, Ill., 1968), pp. 1-308, American Mathematical Society, Providence, RI, USA, 1976.

[31] H. K. Xu, "Iterative algorithms for nonlinear operators," Journal of the London Mathematical Society, vol. 66, no. 1, pp. 240-256, 2002. 


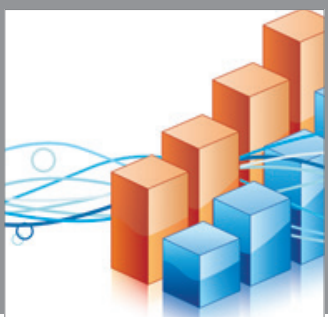

Advances in

Operations Research

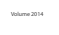

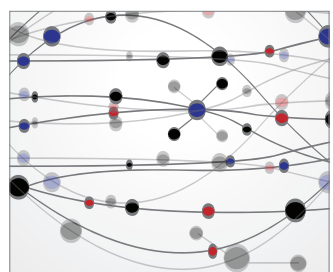

\section{The Scientific} World Journal
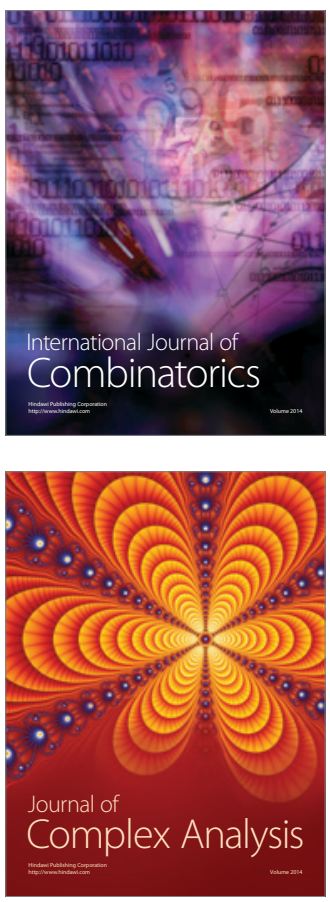

International Journal of

Mathematics and

Mathematical

Sciences
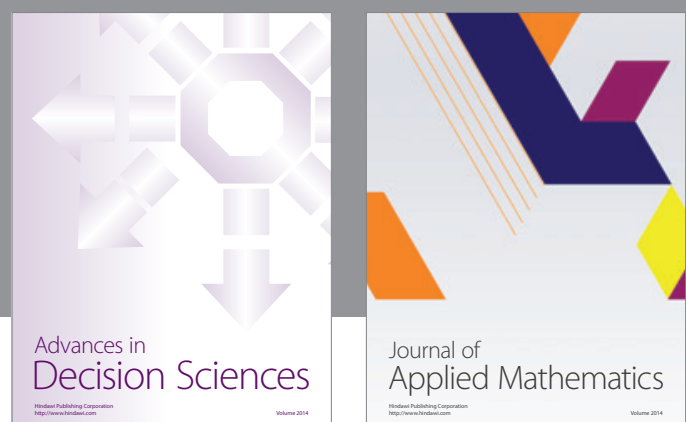

Journal of

Applied Mathematics
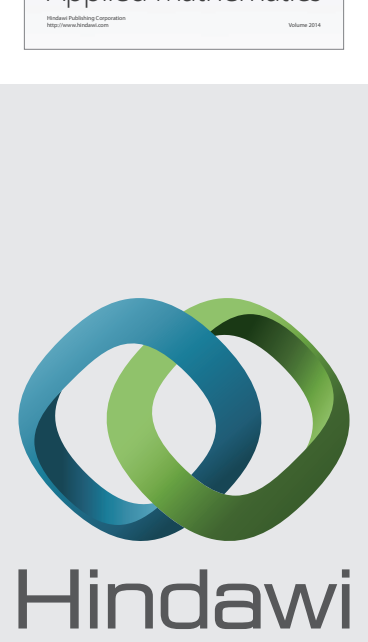

Submit your manuscripts at http://www.hindawi.com
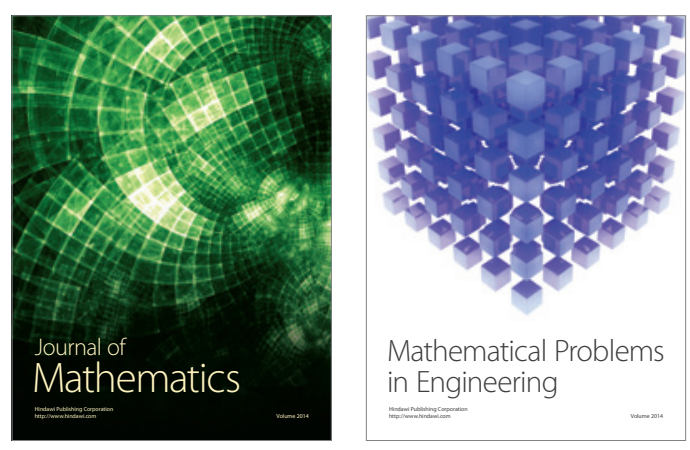

Mathematical Problems in Engineering
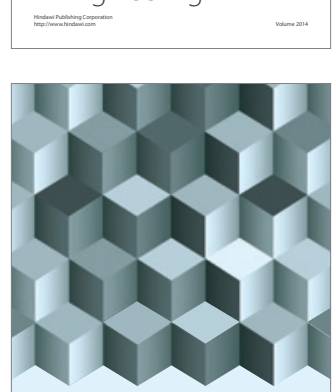

Journal of

Function Spaces
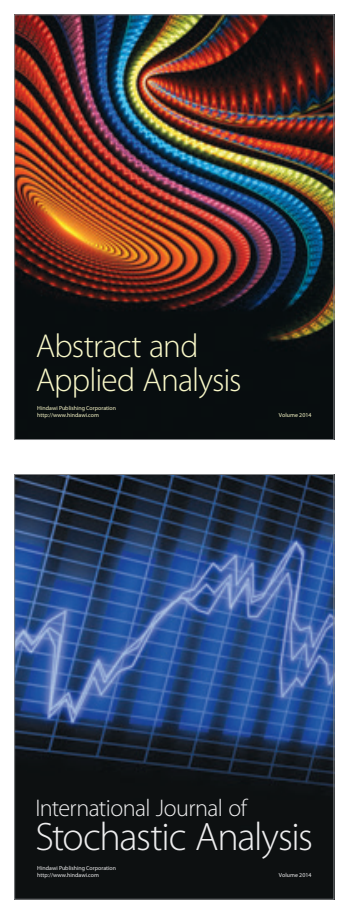

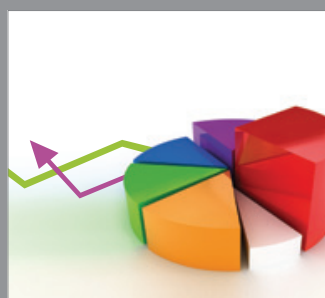

ournal of

Probability and Statistics

Promensencen
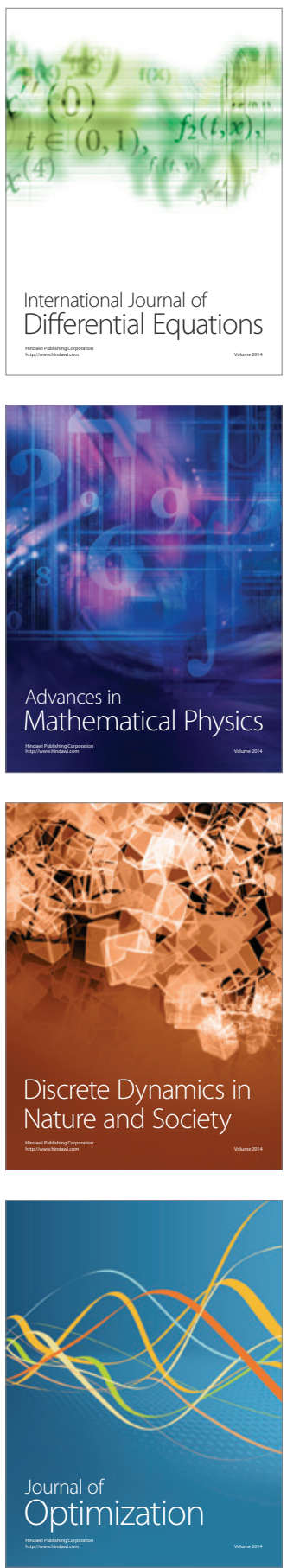